\title{
The effect of pre-pregnancy BMI on intention, initiation and duration of breast-feeding
}

\author{
Isabelle Guelinckx ${ }^{1, *}$, Roland Devlieger ${ }^{2}$, Annick Bogaerts ${ }^{3}$, Sara Pauwels ${ }^{1}$ \\ and Greet Vansant ${ }^{1}$ \\ 'Department of Nutrition-Public Health Medicine, LFoRCe (Leuven Food Science and Nutrition Research Centre), \\ Catholic University, Kapucijnenvoer 35, Box 7001, B-3000 Leuven, Belgium: ${ }^{2}$ Department of Obstetrics and \\ Gynaecology, University Hospital Leuven, Leuven, Belgium: ${ }^{3} \mathrm{PHL}$ Health Care, Limburg Catholic University \\ College, PHL University College, Hasselt, Belgium
}

Submitted 1 February 2011: Accepted 9 September 2011: First published online 31 0ctober 2011

\begin{abstract}
Objective: To determine whether pre-pregnancy BMI influences breast-feeding practice.

Design: Retrospective epidemiological study.

Setting: University Hospital Leuven, Catholic University Leuven, Belgium.

Subjects: Two hundred women (median age 29 years, interquartile range (IQR) 4;

$52 \%$ nulliparae) were grouped into four categories according to pre-pregnancy

BMI using WHO cut-offs.

Results: The incidence of intention and initiation of breast-feeding was significantly lower in underweight (64\%) and obese women (68\%) compared with normal weight (92\%) and overweight women (80\%). Initiation was also related to parity $(\mathrm{OR}=0.582 ; 95 \% \mathrm{CI} 0 \cdot 400,0 \cdot 846)$, but not to gestational weight gain, method of delivery or hypertensive disorders. Fifty-two per cent of underweight, $70 \%$ of normal weight and $56 \%$ of overweight women were exclusively breastfeeding their infant during the first month of life. This incidence was significantly lower in the obese group (34\%; $P=0 \cdot 030)$. Only $40 \%$ of all infants were exclusively breast-fed at 3 months of age, with the lowest prevalence among women with obesity $(P=0.001)$. The median duration of any breast-feeding in the obese group $(1 \cdot 8$ months, IQR $3 \cdot 4)$ was significantly shorter than in the underweight $(3 \cdot 0$ months, IQR $3 \cdot 1)$, normal weight $(3 \cdot 0$ months, IQR $2 \cdot 4)$ and overweight group $(3 \cdot 0$ months, IQR $3 \cdot 5 ; P=0 \cdot 024)$. Reasons given for ceasing breast-feeding in the obese group were maternal complications (29\%), insufficient milk supply (23\%), sucking problems (21\%) and work resumption (21\%). Conclusions: Breast-feeding practice in the total population, but especially among women with obesity, fell short of global WHO recommended standards. Policy initiatives and local interventions should continue to support breast-feeding, but also prevent maternal obesity.
\end{abstract}

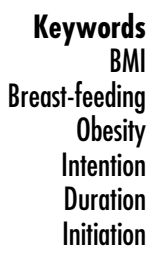

Breast-feeding is the most natural way of nurturing young infants. Even though virtually all mothers can breast-feed, only $64 \cdot 8 \%$ of the Belgian infants in 2007 were exclusively breast-fed at day 6 of life ${ }^{(1)}$. Interventions to promote intention, initiation and duration of breast-feeding are clearly required. One of the recommendations on the level of clinical practice is implementation of the WHO/ UNICEF Baby-Friendly Hospital Initiative (BFHI) ${ }^{(2)}$. The BFHI has been shown to increase the rates of exclusive breast-feeding at 3 and 6 months of age ${ }^{(3,4)}$. During the recruitment period of the present study, the University Hospital Leuven was in the running to become a BabyFriendly Hospital. Therefore strategies to fully implement 'The Ten Steps to Successful Breastfeeding' published by WHO were in development and tried out in practice.
The year after the survey (2008), the hospital received Baby-Friendly accreditation.

The aim of the present study was to evaluate the status of the breast-feeding practice of patients treated at the University Hospital Leuven. Since the prevalence of prepregnancy overweight and obesity among pregnant women in this centre was $29 \%$ in 2006 , specific attention was given to the intention, initiation and duration of breast-feeding among overweight and obese women.

\section{Methods}

The present retrospective epidemiological study was conducted in a sample of 200 women who delivered at the 


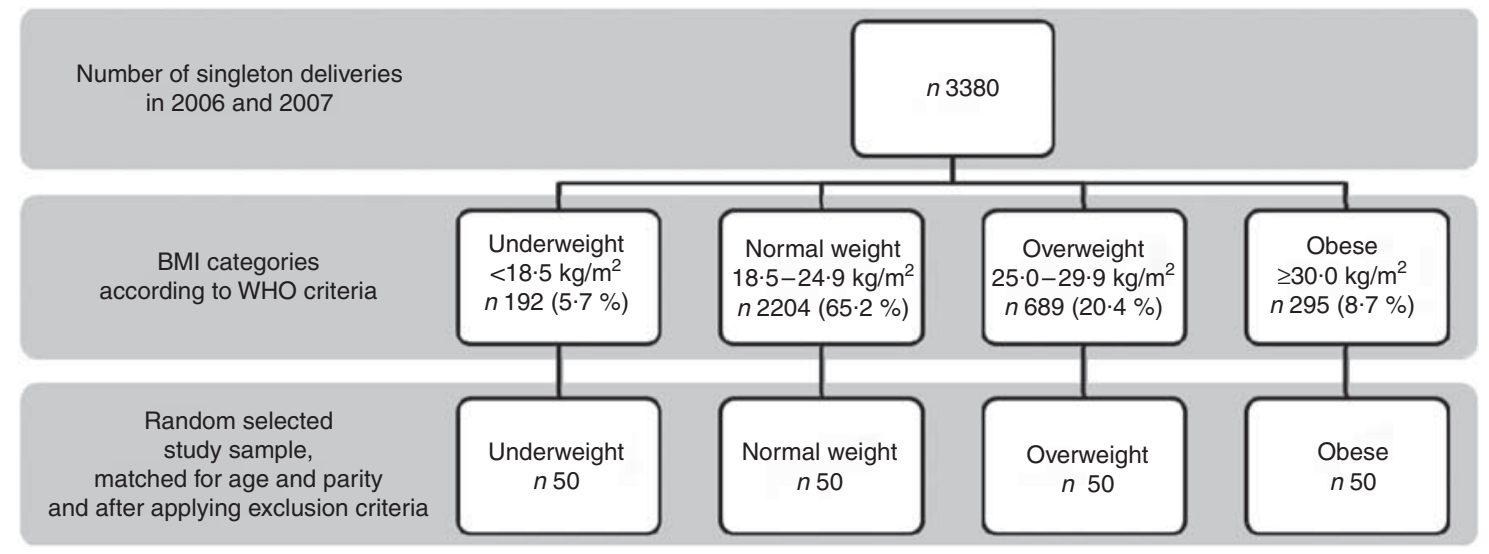

Fig. 1 Flowchart of recruitment of participants into the study

antenatal clinic, Department of Obstetrics and Gynecology, University Hospital Leuven, Belgium. The study was approved by the Ethics Committee for Human Experimentation of the Faculty of Medicine, Catholic University of Leuven. All participants signed written informed consent.

\section{Study population}

All pregnancy charts of women attending prenatal care for a singleton pregnancy and delivering a living infant at the department in 2006 and 2007 ( $n$ 3380) were studied. The women were assigned to four groups according to pre-pregnancy BMI using WHO cut-offs: underweight, BMI $<18.5 \mathrm{~kg} / \mathrm{m}^{2}$; normal weight, BMI $=18 \cdot 5-24.9 \mathrm{~kg} / \mathrm{m}^{2}$; overweight, $\quad$ BMI $=25 \cdot 0-29 \cdot 9 \mathrm{~kg} / \mathrm{m}^{2} ;$ and obese, BMI $\geq 30 \cdot 0 \mathrm{~kg} / \mathrm{m}^{2}$ (Fig. 1) ${ }^{(5)}$. Pre-pregnancy BMI was calculated by dividing the maternal pre-pregnancy weight in kilograms by the square of height in metres $\left(\mathrm{kg} / \mathrm{m}^{2}\right)$. Out of each BMI group a random sample of fifty charts was selected in such a way that the mean age and parity between the groups were comparable. Subsequently the following exclusion criteria were applied: pre-existing diabetes, inadequate knowledge of the Dutch language and missing contact information. If a woman was excluded, she was randomly replaced by another woman.

\section{Clinical parameters}

The following data were obtained from the paper pregnancy charts: pre-pregnancy weight and height, weight on the day of delivery and information concerning parity, age of the mother, smoking behaviour at the start of the pregnancy, gestational diabetes (GDM), pregnancyinduced hypertension (PIH) and chronic hypertension, pre-eclampsia, gestational length, induction of labour, method of delivery, birth weight and height, macrosomia (defined as birth weight $>4 \cdot 0 \mathrm{~kg}$ ), low birth weight (defined as birth weight $<2 \cdot 5 \mathrm{~kg}$ ), Apgar score after 1 and $5 \mathrm{~min}$, and admission to intensive neonatal care. In the case of missing or contradicting data concerning the mentioned parameters, the electronic registration data were consulted. Pre-pregnancy weight was self-reported.
The height of the participants was measured once at the first visit, using a microtoise, to the nearest $0.5 \mathrm{~cm}$. Total gestational weight gain (GWG) was defined as weight on the day of delivery minus pre-pregnancy weight. GWG was evaluated according to recommendations of the US Institute of Medicine: $12 \cdot 5-18 \mathrm{~kg}$ for underweight women, $11 \cdot 5-16 \mathrm{~kg}$ for normal weight women, $7 \cdot 0-11.5 \mathrm{~kg}$ for overweight women and $5 \cdot 0-9 \cdot 0 \mathrm{~kg}$ for obese women ${ }^{(6)}$. Gestational age was determined from the known date of the last menstrual period or the sonographic first-trimester crown-rump length, corrected to the latter if the difference between these two parameters exceeded $5 \mathrm{~d}$. Blood pressure measurements and urine screening for proteinuria and glucosuria were performed at each antenatal visit, and a $50 \mathrm{~g}$ glucose challenge test at 24-28 weeks of gestation was administered to all participants. GDM was diagnosed with the Carpenter and Coustan criteria using two or more abnormal plasma glucose values (fasting $>95 \mathrm{mg} / \mathrm{dl}$, postchallenge: $1 \mathrm{~h}>180 \mathrm{mg} / \mathrm{dl}, 2 \mathrm{~h}>155 \mathrm{mg} / \mathrm{dl}, 3 \mathrm{~h}>140 \mathrm{mg} /$ dl $)^{(7)}$. The diagnosis of PIH was made according to guidelines of the International Society for the Study of Hypertension in Pregnancy as follows: de novo blood pressure $\geq 140 / 90 \mathrm{mmHg}$ appearing after 20 weeks of gestation. Preeclampsia was defined as the presence of PIH or chronic hypertension in combination with proteinuria ${ }^{(8)}$.

\section{Breast-feeding questionnaire}

Data were collected using a structured questionnaire on breast-feeding practice via a telephone interview between months 3 and 6 of the postpartum period. This questionnaire was based primarily on a questionnaire investigating the nutritional habits of infants by University Hasselt (SEIN), but was adapted and tested within our department ${ }^{(9)}$. The questionnaire consisted of eleven questions in Dutch (Appendix 1); an English version of the questionnaire, which was cross validated, is given in Appendix 2. Exclusive breast-feeding was defined as consumption solely of breast milk from birth; so there is no consumption of formula feeding or solid baby foods (fruit and vegetables) and less than weekly consumption 
of fluids other than water. When analysing the results, the reasons for ceasing breast-feeding could be grouped into six categories: (i) sucking problems, (ii) resumption of work, (iii) maternal physical complications, (iv) insufficient milk production and (v) motives related to social life. Additionally, (vi) some participants interpreted the WHO recommendations in such a way that they stopped breast-feeding completely at 6 months postpartum. Maternal physical complications included maternal illness, complications related to breast-feeding such as mastitis, sore nipples/fissures or extreme tiredness.

\section{Statistical analysis}

All analyses were performed using the SPSS for Windows statistical software package release $16 \cdot 0$ (SPSS Inc., Chicago, IL, USA). A two-sided level of significance of 0.05 was defined. The continuous variables were analysed using ANOVA followed by post hoc tests. However, the assumption of normal distribution was not fulfilled for all continuous variables describing the population (age, pre-pregnancy weight, height and BMI). They were therefore presented as median (interquartile range, IQR) and tested with a KruskalWallis test. Categorical variables were analysed using the $\chi^{2}$ test. Logistic regression models with initiation as dependent variable, and pre-pregnancy BMI, age, smoking, parity, GWG, pregnancy duration, mode of delivery or hypertensive disorders as independent variables, were also fitted. Pre-pregnancy BMI was entered as a continuous variable as well as a categorical variable (normal weight and overweight $v$. underweight and obesity).

Since preterm birth could significantly influence breastfeeding practice, all analyses were performed with and without woman who delivered preterm. However this did not result in statistically significant differences in any of the studied parameters, and therefore all participants remained included.

\section{Results}

The characteristics of the participants and the newborns are summarized in Table 1 . In the overweight and obese groups, PIH, excessive GWG and induction of labour were more prevalent than in the underweight and normal weight groups. The highest prevalence of preterm birth was observed in the overweight group. The prevalence of chronic hypertension was increased in the obese group compared with the other three groups.

The results of the questionnaire on breast-feeding practice indicated that significantly fewer underweight and obese women intended to breast-feed $(P=0 \cdot 004)$ and eventually also initiated breast-feeding $(P=0 \cdot 002$; Table 2). Fifty-two per cent, $70 \%$ and $56 \%$ of the underweight, normal weight and overweight women, respectively, were exclusively breast-feeding their infant during the entire first month of life. Compared with these groups, significantly fewer obese women (34\%) were exclusively breast-feeding during the entire first month $(P=0 \cdot 030)$. No statistical difference could be found in the initiation of breast-feeding between smokers (56\%) and non-smokers (77\%; $P=0 \cdot 064)$. The incidence of exclusive breast-feeding during the third month of life was also significantly influenced by the pre-pregnancy BMI $(P=0 \cdot 001)$. In the total population only $40 \%$ of the infants were exclusively breast-fed at 3 months of age. In the case of any breast-feeding at 3 months of age, obese women (52\%) fed significantly less on demand than did underweight $(87 \%)$, normal weight $(71 \%)$ or overweight women $(71 \% ; P=0 \cdot 030)$.

The same results were shown by the logistic regression models. Initiation of breast-feeding was less likely in the case of maternal underweight or obesity $(\mathrm{OR}=0 \cdot 302$; $95 \%$ CI $0 \cdot 150,0 \cdot 608)$. With increasing parity the likeliness of initiating breast-feeding decreased (OR $=0.582 ; 95 \%$ CI $0 \cdot 400,0 \cdot 846)$. Maternal age, GWG, pregnancy duration, smoking, having a Caesarean section or hypertensive disorders did not significantly affect initiation of breast-feeding.

The median duration of any breast-feeding in the obese group was also significantly shorter than in the other BMI groups: median time point of cessation of breast-feeding was 1.8 (IQR 3.4) months in the obese group compared with $3 \cdot 0($ IQR $3 \cdot 1)$ months, $3 \cdot 0$ (IQR 2.4) months and $3 \cdot 0$ (IQR 3.5) months in the underweight, normal weight and overweight group, respectively $(P=0 \cdot 024)$.

Besides the intention, initiation and duration of breastfeeding, the motives to cease breast-feeding were also different between the BMI groups (Table $2 ; P=0 \cdot 041$ ). In the total population eleven (7\%) women reported that they stopped any breast-feeding after 6 months because this was their interpretation of the WHO breast-feeding recommendations.

\section{Discussion}

The present observational study reveals that prepregnancy BMI is one of the factors determining breastfeeding practice. Pre-pregnancy obesity is associated with lower intention and initiation of breast-feeding and reduced duration of any breast-feeding. This association is in accordance with results of a systematic review on this topic ${ }^{(10)}$. However, pre-pregnancy underweight was also associated with lower intention and initiation, which is in contradiction to previous findings ${ }^{(11)}$. These observations between pre-pregnancy BMI and breast-feeding intention are only associations, and do not necessarily imply a causal relationship. Others have investigated the cause of this reduced incidence of intention to breast-feed among obese women and suggest that medical, anatomic, sociocultural and psychological factors are involved ${ }^{(10,12)}$. Medical factors that can influence breast-feeding practice 
Table 1 Characteristics of the study population: sample of pregnant women who delivered at University Hospital Leuven, Belgium, 2006 and 2007

\begin{tabular}{|c|c|c|c|c|c|c|c|c|c|c|c|}
\hline & & & \multicolumn{8}{|c|}{ BMI category $\left(\mathrm{kg} / \mathrm{m}^{2}\right)$} & \multirow[b]{3}{*}{$P$ value } \\
\hline & \multicolumn{2}{|c|}{$\begin{array}{l}\text { Total population } \\
\quad(n 200)\end{array}$} & \multicolumn{2}{|c|}{$\begin{array}{l}\text { Underweight }<18.5 \\
(n 50)\end{array}$} & \multicolumn{2}{|c|}{$\begin{array}{l}\text { Normal weight } 18 \cdot 5-24 \cdot 9 \\
\qquad(n 50)\end{array}$} & \multicolumn{2}{|c|}{$\begin{array}{l}\text { Overweight } 25 \cdot 0-29 \cdot 9 \\
(n 50)\end{array}$} & \multicolumn{2}{|c|}{$\begin{array}{l}\text { Obese } \geq 30 \cdot 0 \\
(n 50)\end{array}$} & \\
\hline & Median or $n$ & IQR or $\%$ & Median or $n$ & IQR or $\%$ & Median or $n$ & IQR or $\%$ & Median or $n$ & IQR or \% & Median or $n$ & IQR or \% & \\
\hline \multicolumn{12}{|l|}{ Mother's characteristics } \\
\hline Age (years) & 29 & 4 & 31 & 6 & 29 & 4 & 29 & 5 & 29 & 2 & 0.052 \\
\hline Pre-pregnancy weight (kg) & $68 \cdot 0$ & $28 \cdot 0$ & $50 \cdot 0$ & $5 \cdot 0$ & $61 \cdot 0$ & $11 \cdot 2$ & $76 \cdot 7$ & $6 \cdot 4$ & $93 \cdot 0$ & $15 \cdot 8$ & 0.001 \\
\hline Pre-pregnancy BMI $\left(\mathrm{kg} / \mathrm{m}^{2}\right)$ & $23 \cdot 3$ & $10 \cdot 0$ & $17 \cdot 9$ & $1 \cdot 1$ & $21 \cdot 4$ & $3 \cdot 4$ & $27 \cdot 4$ & $1 \cdot 4$ & $33 \cdot 2$ & 4.9 & 0.001 \\
\hline Gestational weight gain $(\mathrm{kg})$ & $14 \cdot 0$ & $6 \cdot 6$ & $13 \cdot 8$ & $6 \cdot 9$ & $14 \cdot 9$ & $3 \cdot 8$ & $15 \cdot 1$ & $7 \cdot 9$ & $8 \cdot 6$ & $9 \cdot 3$ & 0.001 \\
\hline Nullipara & 104 & 52 & 23 & 46 & 30 & 60 & 26 & 52 & 25 & 50 & 0.555 \\
\hline Smoking & 16 & 8 & 8 & 16 & 3 & 6 & 1 & 2 & 4 & 8 & 0.070 \\
\hline $\mathrm{PIH}$ & 39 & 20 & 3 & 6 & 4 & 8 & 13 & 26 & 19 & 39 & 0.001 \\
\hline Chronic hypertension & 10 & 5 & 0 & 0 & 2 & 4 & 2 & 4 & 6 & 12 & 0.001 \\
\hline Pre-eclampsia & 4 & 2 & 2 & 4 & 2 & 4 & 0 & 0 & 0 & 0 & 0.253 \\
\hline Induction of labour & 69 & 35 & 10 & 20 & 11 & 22 & 26 & 52 & 22 & 44 & 0.005 \\
\hline Caesarean section & 32 & 17 & 6 & 13 & 8 & 18 & 7 & 17 & 11 & 22 & 0.534 \\
\hline \multicolumn{12}{|l|}{ Infant's characteristics } \\
\hline Birth weight (g) & 3445 & 535 & 3245 & 617 & 3485 & 551 & 3515 & 678 & 3440 & 383 & 0.203 \\
\hline Macrosomia $(>4000 \mathrm{~g})$ & 19 & 10 & 2 & 4 & 2 & 4 & 10 & 20 & 5 & 10 & 0.079 \\
\hline Infant length (cm) & $50 \cdot 5$ & $3 \cdot 0$ & $50 \cdot 0$ & $2 \cdot 0$ & $51 \cdot 0$ & $2 \cdot 2$ & $51 \cdot 0$ & $2 \cdot 0$ & $51 \cdot 0$ & $2 \cdot 8$ & 0.688 \\
\hline Preterm birth $<37$ weeks & 16 & 8 & 2 & 4 & 5 & 10 & 8 & 16 & 1 & 2 & 0.043 \\
\hline Admission to neonatal IC & 21 & 11 & 2 & 4 & 7 & 14 & 4 & 8 & 8 & 16 & $0 \cdot 184$ \\
\hline
\end{tabular}

IQR, interquartile range; PIH, pregnancy-induced hypertension; IC, intensive care.

Continuous variables are presented as median and IQR, and analysed with the Kruskal-Wallis test. Dichotomous variables are presented as number and percentage, and analysed with the $\chi^{2}$ test. 
Table 2 Breast-feeding practices in the total study population and according to BMI category: sample of pregnant women who delivered at University Hospital Leuven, Belgium, 2006 and 2007

\begin{tabular}{|c|c|c|c|c|c|c|c|c|c|c|c|}
\hline & & & \multicolumn{8}{|c|}{ BMI category $\left(\mathrm{kg} / \mathrm{m}^{2}\right)$} & \multirow[b]{3}{*}{$P$ value } \\
\hline & \multicolumn{2}{|c|}{$\begin{array}{l}\text { Total population } \\
\quad(n \text { 200) }\end{array}$} & \multicolumn{2}{|c|}{$\begin{array}{l}\text { Underweight } \\
<18.5(n 50)\end{array}$} & \multicolumn{2}{|c|}{$\begin{array}{c}\text { Normal weight } \\
18 \cdot 5-24 \cdot 9(n=50)\end{array}$} & \multicolumn{2}{|c|}{$\begin{array}{c}\text { Overweight } \\
25 \cdot 0-29 \cdot 9(n=50)\end{array}$} & \multicolumn{2}{|c|}{$\begin{array}{l}\text { Obese } \geq 30 \cdot 0 \\
\quad(n=50)\end{array}$} & \\
\hline & Median or $n$ & IQR or \% & Median or $n$ & IQR or \% & Median or $n$ & IQR or $\%$ & Median or $n$ & IQR or \% & Median or $n$ & IQR or $\%$ & \\
\hline \multicolumn{12}{|l|}{ Continuous variables } \\
\hline $\begin{array}{l}\text { Time interval between birth and first } \\
\text { suckling (min) }\end{array}$ & $20 \cdot 0$ & $50 \cdot 0$ & $30 \cdot 0$ & $49 \cdot 4$ & $17 \cdot 5$ & $51 \cdot 2$ & $15 \cdot 0$ & $24 \cdot 4$ & $30 \cdot 0$ & $46 \cdot 2$ & $0 \cdot 345$ \\
\hline Number of feeds/d & 6 & 2 & 6 & 2 & 6 & 2 & 6 & 2 & 6 & 3 & $0 \cdot 258$ \\
\hline Time point of ceasing exclusive BF (month) & $3 \cdot 0$ & $3 \cdot 1$ & $3 \cdot 3$ & $3 \cdot 8$ & $3 \cdot 0$ & $2 \cdot 8$ & $3 \cdot 3$ & $3 \cdot 8$ & $2 \cdot 1$ & $2 \cdot 9$ & 0.039 \\
\hline \multicolumn{12}{|l|}{ Categorical variables } \\
\hline Intention to BF & 152 & 76 & 32 & 64 & 46 & 92 & 40 & 80 & 34 & 68 & 0.004 \\
\hline Initiation of BF & 151 & 76 & 31 & 62 & 46 & 92 & 40 & 80 & 34 & 68 & $0 \cdot 002$ \\
\hline \multicolumn{12}{|l|}{ Nutrition during the entire first month } \\
\hline Exclusive BF & 105 & 53 & 26 & 52 & 34 & 70 & 28 & 56 & 17 & 34 & \\
\hline Bottle-feeding & 49 & 25 & 19 & 38 & 4 & 8 & 10 & 20 & 16 & 33 & \\
\hline Combination BF and bottle-feeding & 44 & 22 & 5 & 10 & 11 & 22 & 12 & 24 & 16 & 33 & 0.001 \\
\hline Exclusive BF for 3 months & 79 & 40 & 18 & 36 & 30 & 60 & 20 & 40 & 11 & 22 & 0.001 \\
\hline $\begin{array}{l}\text { BF on demand } \\
\text { Motives to cease BF }\end{array}$ & 97 & 70 & 24 & 87 & 31 & 71 & 24 & 71 & 15 & 52 & $0 \cdot 030$ \\
\hline Resume work & 58 & 38 & 14 & 45 & 26 & 57 & 11 & 28 & 7 & 21 & \\
\hline Physical complication & 34 & 23 & 4 & 13 & 9 & 20 & 11 & 28 & 10 & 29 & \\
\hline Insufficient milk & 29 & 19 & 8 & 26 & 6 & 13 & 7 & 18 & 8 & 24 & \\
\hline Sucking problems & 17 & 11 & 0 & 0 & 3 & 7 & 7 & 17 & 7 & 21 & \\
\hline WHO recommendations & 11 & 7 & 4 & 13 & 2 & 4 & 3 & 7 & 2 & 6 & \\
\hline Motives related to social life & 2 & 1 & 1 & 3 & 0 & 0 & 1 & 3 & 0 & 0 & 0.041 \\
\hline
\end{tabular}

IQR, interquartile range; BF, breast-feeding.

Continuous variables are presented as median and IQR, and analysed with the Kruskal-Wallis test. Dichotomous variables are presented as number and percentage, and analysed with the $\chi^{2}$ test. 
of obese women are the presence of polycystic ovary syndrome, diabetes, or experiencing obstetric complications or a Caesarean delivery ${ }^{(10,12)}$. Women who have a Caesarean birth have less mother-infant contact after birth and delayed first latching-on of the infant. This can lead to a delayed lactogenesis II, especially in combination with macrosomia which is more prevalent in obese women $^{(13)}$. Macrosomia is associated with unstable glucose values and oral glucose supplementation, interacting negatively with milk production and excretion ${ }^{(14,15)}$. In the present study, however, no statistical association was found between the occurrence of Caesarean section and breast-feeding initiation. Note that in the present study no significant difference was found in the incidence of Caesarean section among BMI groups, even though maternal obesity in the literature is often associated with a higher rate of Caesarean section ${ }^{(13)}$. This might explain the lack of association between obesity, Caesarean section and lactation. Anatomic factors include difficulties due to large breasts ${ }^{(10,16)}$. Supporting the breast and assisting the infant to latch-on correctly at the same time tends to be more difficult with larger breasts ${ }^{(17)}$. Sociocultural factors include lower socio-economic status and participation of obese women in health behaviour programmes ${ }^{(10)}$. Mok et al. ${ }^{(18)}$ observed that despite the greater breast-feeding difficulties, obese mothers were less likely to seek support for breast-feeding. Shame, discomfort to breast-feed in public, depression and a low body image are all psychological factors which decrease the likeliness of initiating breast-feeding ${ }^{(10,18)}$. Investigating the influence of anatomic, socio-cultural and psychological factors on breast-feeding intention was beyond the scope of the present study.

The reasons to cease any breast-feeding were investigated however. Half of underweight and normal weight mothers in the present study abandoned breast-feeding completely before the recommended 6 months because they started working again. WHO recommends that a new mother should have at least 16 weeks of absence from work after delivery, to be able to rest and breast-feed her child $^{(19)}$. In Belgium a mother is entitled to 15 weeks of maternity leave, with a maximum of 14 weeks in the postpartum period. Similar arrangements exist in France (16 weeks), The Netherland (16 weeks), Germany (14 weeks) and Spain $(16 \text { weeks })^{(20)}$. In the United Kingdom the maternity leave is set at 52 weeks but an even more generous parental leave is offered in Sweden ${ }^{(20)}$. All working parents are entitled to 16 months paid leave per child, the cost being shared between the employer and the state $^{(20)}$. However, a longer maternity leave does not always necessarily imply a longer breast-feeding duration: the maternity leave in Switzerland (16 weeks) is comparable to that in Belgium and yet the mean duration of any breastfeeding is higher ( 31 weeks) ${ }^{(21)}$ than the median duration of 12 weeks in the present study. The workplace could be also a barrier to continue any breast-feeding. Mothers need access to a safe, clean and private place in or near their workplace to continue the breast-feeding practice or to express breast milk. Resuming work however was not the main reason to cease breast-feeding among overweight and obese mothers. Insufficient milk supply and maternal complications were as prevalent reasons as work resumption in these BMI groups. The assumption can be made that again the same medical, anatomic, socio-cultural and psychological factors mentioned above could be responsible for the reduced duration of breast-feeding ${ }^{(12)}$. Other factors associated with breast-feeding cessation could be lack of knowledge and midwifery assistance, or social influences ${ }^{(22)}$. Health-care providers can assist in overcoming the anatomic, socio-cultural and psychological barriers present among obese women. This could for example include avoiding Caesarean delivery whenever possible, introducing techniques to stimulate milk production, utilizing a towel roll to stabilize the larger breast and extra individual support to ensure correct latching-on to the obese breast ${ }^{(23)}$. Techniques to discreetly nurse an infant can be taught and in the case of any signs of postpartum depression, special assistance should be offered. A social worker could be involved in cases of lower socialeconomic situation. These last interventions are designed to facilitate the initiation and duration of breast-feeding among obese women. However, preventing the initial cause of reduced breast-feeding practice, namely maternal obesity, is as important.

The strength of the current study is the presence of all four BMI groups with an equal group size. The possible weaknesses of the study lie in the relatively small sample size and the use of a telephone interview: the interview was conducted after breast-feeding cessation. Consequently the results are liable to recall bias.

To conclude, breast-feeding practice is a multifactor behaviour of which pre-pregnancy BMI is one of the factors. Since maternal obesity is associated with a lower initiation and reduced duration of breast-feeding, interventions on a national policy level, in clinical practice and on the individual level are required to prevent maternal obesity, to promote breast-feeding and to facilitate breast-feeding over a longer time period in this growing population.

\section{Acknowledgements}

I.G. was funded by a postdoctoral grant from the $\mathrm{KU}$ Leuven (2010-2011). R.D. is the recipient of a postdoctoral research grant from the FWO Flanders (2010-2015). There are no conflicts of interest. I.G. collected and analysed the data, together with G.V. Interpretation of data and writing of the manuscript were performed by I.G., G.V. and R.D. A.B. and S.P. critically reviewed the article. All authors read the final version of the manuscript and approved submission. 


\section{References}

1. Kind \& Gezin (2009) Het kind in Vlaanderen 2009. Brussel: Kind \& Gezin.

2. World Health Organization (2001) Global Strategy for Infant and Young Child Feeding, The Optimal Duration of Exclusive Breastfeeding. Geneva: WHO.

3. Chung M, Raman G, Trikalinos T et al. (2008) Interventions in primary care to promote breastfeeding: an evidence review for the US Preventive Services Task Force. Ann Intern Med 149, 565-582.

4. Spiby H, McCormick F, Wallace L et al. (2009) A systematic review of education and evidence-based practice interventions with health professionals and breast feeding counsellors on duration of breast feeding. Midwifery 25, 50-61.

5. World Health Organization (2006) Process for a WHO Global Strategy on Diet, Physical Activity and Health. WHA55 23. Geneva: WHO.

6. Institute of Medicine (2009) Weight Gain During Pregnancy: Reexamining the Guidelines. Washington, DC: National Academy Press.

7. Carpenter M \& Coustan DR (1982) Criteria for screening tests for gestational diabetes. Am J Obest Gynecol 144, 768-773.

8. Brown DM, Lindheimer M, de Swiet M et al. (2001) The classification and diagnosis of the hypertensive disorders of pregnancy: statement from the International Society for the Study of Hypertension in Pregnancy (ISSHP). Hypertens Pregnancy 20, 9-14.

9. Lenaers S, Goffin I, Alliet P et al. (2002) Onderzoek naar de voedingssituatie van jonge kinderen. Diepenbeek: Limburgs Universitair Centrum SEIN.

10. Amir LH \& Donath S (2007) A systematic review of maternal obesity and breastfeeding intention, initiation and duration. BMC Pregnancy Childbirth 7, 9.

11. Giovannini M, Radaelli G, Banderali G et al. (2007) Low prepregnant body mass index and breastfeeding practices. J Hum Lact 23, 44-51.
12. Rasmussen KM (2007) Association of maternal obesity before conception with poor lactation performance. Annu Rev Nutr 27, 103-121.

13. Guelinckx I, Devlieger R, Beckers K et al. (2008) Maternal obesity: pregnancy complications, gestational weight gain and nutrition. Obes Rev 9, 140-150.

14. Forster DA, McLachlan HL \& Lumley J (2006) Factors associated with breastfeeding at six months postpartum in a group of Australian women. Int Breastfeed J 1, 18.

15. Dewey KG, Nommsen-Rivers LA, Heinig MJ et al. (2003) Risk factors for suboptimal infant breastfeeding behavior, delayed onset of lactation, and excess neonatal weight loss. Pediatrics 112, 607-619.

16. Rasmussen KM \& Kjolhede CL (2004) Prepregnant overweight and obesity diminish the prolactin response to suckling in the first week postpartum. Pediatrics 113, e465-e471.

17. Walker M (2006) Influence of the Maternal Anatomy and Physiology on Lactation. Sudbury, MA: Jones and Barlett Publishers.

18. Mok E, Multon C, Piguel L et al. (2008) Decreased full breastfeeding, altered practices, perceptions, and infant weight change of prepregnant obese women: a need for extra support. Pediatrics 121, e1319-e1324.

19. World Health Organization (2009) Infant and Young Child Feeding: Model Chapter for Textbooks for Medical Students and Allied Health Professionals. Geneva: WHO.

20. International Labour Organization (2010) Maternity at Work: A Review of National Legislation. Findings from the ILO's Conditions of Work and Employment Database, 2nd ed. Geneva: ILO.

21. Merten S, Dratva J \& Ackermann-Liebrich U (2005) Do baby-friendly hospitals influence breastfeeding duration on a national level? Pediatrics 116, e702-e708.

22. Gilmour C, Hall H, McIntyre M et al. (2009) Factors associated with early breastfeeding cessation in Frankston, Victoria: a descriptive study. Breastfeed Rev 17, 13-19.

23. Jevitt C, Hernandez I \& Groer M (2007) Lactation complicated by overweight and obesity: supporting the mother and newborn. J Midwifery Womens Health 52, 606-613.

\section{Appendix 1}

Dutch questionnaire on breast-feeding practice ${ }^{(9)}$

Borstvoedingsvragenlijst (tijdstip: $>3$ maanden postpartum)

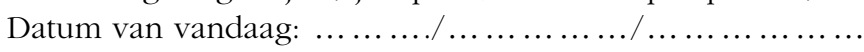

Datum bevalling:

1. Was u aan het begin van de zwangerschap van plan borstvoeding te geven?

- Ja

- Neen

2. Kreeg het kind effectief ooit borstvoeding?

- Ja

- Neen (einde)

3. Hoeveel tijd verstreek tussen de geboorte en de $1^{\mathrm{e}}$ voeding?

..... minuten

4. Kreeg het kind de volledige $1^{\mathrm{e}}$ maand borstvoeding (eventueel in combinatie met flesvoeding)?

- Neen

- Ja: ○ enkel borstvoeding

$\circ$ gemengde voeding 
5. Welke lichamelijke symptomen had de moeder?

- Geen

- Ja: $\circ$ borstontsteking
o tepelkloven
$\circ$ pijn bij zuigen
$\circ$ stuwing
$\circ$ melkverlies
$\circ$ vermoeidheid

6. Krijgt uw kind nog steeds borstvoeding (eventueel in combinatie met andere voeding)?

- Neen (ga naar vraag 10)

- Ja: $\circ$ enkel borstvoeding

$\circ$ gemengde voeding

7. Krijgt het kind borstvoeding op vaste tijdstippen of op vraag?

- Vaste tijdstippen

- Op vraag

8. Hoeveel keren per dag krijgt het kind borstvoeding?

9. Hoe lang duurt de borstvoeding?

- $<15 \mathrm{~min}$

- $15-30 \mathrm{~min}$

- 30-60 min

- $60 \mathrm{~min}$

10. Wanneer stopte u met borstvoeding?

11. Wat was de voornaamste reden tot stoppen?

\section{Appendix 2}

\section{English version of the questionnaire on breast-feeding practice}

Breast-feeding questionnaire (time point: $>3$ months of age)

Date:

Date of delivery:

1. Did you plan to breast-feed already at the beginning of your pregnancy?

- Yes

- No

2. Did you actually breast-feed your baby at any time?

- Yes

- No (end)

3. What was the time interval between delivery and the first feeding?

.... minutes

4. Was the baby breast-fed during the complete first month (possibly in combination with bottle-feeding)?

- No

- Yes: $\circ$ exclusive BF

$$
\circ \text { mixed feeding }
$$

5. Did you experience physical complaints from breast-feeding?

- None

- Yes: ○ mastitis

$$
\begin{aligned}
& \text { - sore or fissured nipples } \\
& \text { pain during sucking } \\
& \text { - breast engorgement } \\
& \text { - loss of milk } \\
& \text { - extreme fatigue }
\end{aligned}
$$

6. Is the child still receiving any breast-feeding at this age (possibly combined with complementary feeding)?

- No (go to question 10)

- Yes: ० exclusive BF

$$
\circ \text { mixed feeding }
$$


7. Is the child breast-fed on demand or on schedule?

- regular time points

- on demand

8. How many breast-feeds in one day is the child receiving at this moment?

9. What is the duration of one breast-feed?

- $<15 \mathrm{~min}$

- 15-30 min

- 30-60 min

- $60 \mathrm{~min}$

10. When did you cease breast-feeding?

11. What was the main reason to cease breast-feeding? 